BRUGNOLO MAZAROTTO, Eduardo; GONÇALVES DE QUADROS, Doacir. Ações afirmativas e judicialização da política: um olhar baseado na teoria de John Rawls. Revista Eletrônica Direito e Política, Programa de Pós-Graduação Stricto Sensu em Ciência Jurídica da UNIVALI, Itajaí, v.14, n.1, $1^{\circ}$ quadrimestre de 2019. Disponível em: www.univali.br/direitoepolitica - ISSN 1980-7791

\title{
AÇÕES AFIRMATIVAS E JUDICIALIZAÇÃO DA POLÍTICA: UM OLHAR BASEADO NA TEORIA DE JOHN RAWLS
}

\author{
AFFIRMATIVE ACTIONS AND JUDICIALIZATION OF POLITICS: \\ AN APPROACH BASED ON JOHN RAWLS' THEORY
}

\author{
Eduardo Brugnolo Mazarotto ${ }^{1}$ \\ Doacir Gonçalves de Quadros²
}

\section{RESUMO}

Neste artigo serão abordados alguns aspectos relativos às ações afirmativas do Estado quando, em sua omissão ou falhas nas políticas públicas aplicadas, acabam os direitos de minorias somente sendo resguardados através de interferência judicial, visando garantir acesso a bens e direitos fundamentais. Toda esta problemática será abordada e correlacionada, ainda, na visão do autor John Rawls, com base em sua obra maior "Uma teoria de justiça". Neste sentido, a judicialização da política pode ser interpretada como um procedimento jurisdicional ao qual pugna, em termos concretos, proceder a aplicação do princípio da igualdade e acesso às liberdades e direitos do Estado. Assim sendo, sem o objetivo de esgotamento do tema, será apresentada problematização nesta seara, especialmente quando a judicialização de políticas públicas se coloca em conflito com a dicotomia direito e política.

PALAVRAS-ChaVe: Estado de Bem-estar Social; Ações afirmativas; Judicialização da política; John Rawls; Minorias.

\section{ABSTRACT}

This article will deal with some aspects concerning affirmative actions promoted by the State when, due to the omissions or the flaws of the policies, minorities rigths can only be protected by judicial interference, in order to provide access to fundamental goods and rights. Such a theme will be dealt with based on the views of John Rawls, especially in his major word, A Theory of Justice. In a

\footnotetext{
1 Mestrando no Programa de Mestrado Acadêmico em Direito do Centro Universitário Internacional UNINTER. Advogado. Membro da Comissão de Direito do Terceiro Setor da OAB/PR. Pesquisador no Grupo de Pesquisa Justiça e poder político: a relação entre o campo jurídico e o campo político e a apropriação do direito como recurso de luta política (UNINTER), Curitiba, Paraná, Brasil. E-mail: eduardomazarottoadv@gmail.com

2 Doutor em Sociologia (UFPR). Professor de Ciência Política e do Programa de Mestrado Acadêmico em Direito do Centro Universitário Internacional (Uninter). Coordenador do Grupo de Pesquisa Justiça e poder político: a relação entre o campo jurídico e o campo político e a apropriação do direito como recurso de luta política (UNINTER), Curitiba, Paraná, Brasil. E-mail: dgquadros2001@yahoo.com.br.
} 
BRUGNOLO MAZAROTTO, Eduardo; GONÇALVES DE QUADROS, Doacir. Ações afirmativas e judicialização da política: um olhar baseado na teoria de John Rawls. Revista Eletrônica Direito e Política, Programa de Pós-Graduação Stricto Sensu em Ciência Jurídica da UNIVALI, Itajaí, v.14, n.1, $1^{\circ}$ quadrimestre de 2019. Disponível em: www.univali.br/direitoepolitica - ISSN 1980-7791

rawlsian perspective, the judicialization of politics can be seen as a jurisdictional procedure which aim is to provide, in a concrete way, the application of the principle of the access to equality, liberty and rights. Without intending to exhaust the theme, such a rawlsian perspective on the judicialization of politics will be set on the relationship between the judicialization and the dicotomy Lawpolitics.

Keywords: Welfare State. Affirmative actions. Judicialization of politics. John Rawls. Minorities.

\section{INTRODUÇÃO}

O Estado de Bem-estar Social trouxe consigo um extenso rol de direitos aos indivíduos e que, provenientes de serviços prestados pelo Estado, perfazem um poder assistencial. Com o advento desta formatação de Estado, cujo qual se encontra cada vez mais presente no dia-a-dia das pessoas, diversos fenômenos podem ser relacionados como consequência destas características.

Em outro paralelo, a Teoria da Justiça de John Rawls mostra-se deveras relacionada ao Estado social, pois quando apresentada a visão neocontratualista do autor em questão, observa-se todo o seu constructo de garantias de uma sociedade justa e igualitária, permitindo o acesso aos bens e serviços do Estado em uma nova perspectiva.

Somados os pontos acima levantados, hodiernamente pode-se perceber que ações afirmativas do Estado, na qualidade de políticas públicas com o intento de diminuir desigualdades, têm desencadeado uma série de fenômenos que se originam desta toada. Exemplo disso são os casos denominados de "judicialização da política" ou até mesmo, de ativismo judicial.

O presente artigo objetiva enfrentar alguns elementos das ações afirmativas do Estado sob a égide da Teoria da Justiça de John Rawls, trazendo ao final a discussão acerca do binômio formado pelo judicialização da política e os direitos das minorias, com a finalidade de verificar se possuem guarida na teoria ora em análise e qual a resposta dada por John Rawls acerca desta problemática. 
BRUGNOLO MAZAROTTO, Eduardo; GONÇALVES DE QUADROS, Doacir. Ações afirmativas e judicialização da política: um olhar baseado na teoria de John Rawls. Revista Eletrônica Direito e Política, Programa de Pós-Graduação Stricto Sensu em Ciência Jurídica da UNIVALI, Itajaí, v.14, n.1, $1^{\circ}$ quadrimestre de 2019. Disponível em: www.univali.br/direitoepolitica - ISSN 1980-7791

\section{AS AÇÕES AFIRMATIVAS E O ESTADO DE BEM-ESTAR SOCIAL}

O Estado Assistencial, conhecido como Estado de Bem-estar Social ou welfare state, possui em sua essência influenciar de maneira diversa na sociedade quando comparado com o Estado liberal, como sendo aquele que irá se abster de influir em determinadas questões.

O Estado de Bem-estar Social ${ }^{3}$ pode ser definido, em uma primeira análise e segundo Gloria Regonini, como sendo o Estado que garante formas mínimas de renda, habitação, alimentação, educação, saúde e outros benefícios. Tais garantias são asseguradas a todos os cidadãos e não perfazem atos de caridade por parte do Poder Público, mas sim se emanam na qualidade de direitos políticos ${ }^{4}$. Este Estado assistencial, se mostra de forma mais enfática nos meandros pós segunda-guerra, mais especificamente na Grã-Bretanha, quando se aprovou diversas formas de providência nas searas da saúde e educação, garantidos a todos os cidadãos, sem distinção de classe nem renda 5 .

A transformação do Estado liberal em um Estado social-democrático importou em alterações que não ficaram restritas apenas junto à separação de poderes, mas atingiu também as funções estatais e os órgãos que desempenham as referidas. Além disso, alterou-se a relação de distribuição das funções e seu exercício prático ${ }^{6}$.

É possível notar ainda, que o Estado passa a fornecer a assistência inerente ao welfare state na qualidade de uma opção política e não somente ideológica, pois ainda segundo Gloria Regonini, o Estado Assistencial almeja "o desenvolvimento da democracia e o aumento do poder político das organizações operárias [...],

\footnotetext{
3 De acordo com Elival da Silva Ramos, o Estado de bem estar social é o ambiente próprio para propulsão do fator denominado ativismo judicial e que na sequência deste trabalho será abordado: "É nesse sentido que se pode dizer que o próprio modelo de Estado-providência constitui força impulsionadora do ativismo judicial, levando juízes e tribunais, a revelar, em algumas situações, a existência de limites impostos pelo próprio ordenamento jurídico cuja atuação Ihes incumbe, na ilusão de poderem "queimar" etapas, concretizando, no presente, o programa que a Constituição delineou prospectivamente". RAMOS, Elival da Silva. Ativismo judicial: parâmetros dogmáticos. São Paulo: Saraiva, 2010, p. 271.
}

4 REGONINI, Gloria. Estado de Bem Estar. In: BOBBIO, Norberto et al. (orgs.). Dicionário de política. 5. ed. Brasília: Editora Universidade de Brasília, 2000, p. 416.

${ }^{5}$ REGONINI, Gloria. Estado de Bem Estar, p. 416

${ }^{6}$ RAMOS, Elival da Silva. Ativismo judicial: parâmetros dogmáticos, p. 153. 
BRUGNOLO MAZAROTTO, Eduardo; GONÇALVES DE QUADROS, Doacir. Ações afirmativas e judicialização da política: um olhar baseado na teoria de John Rawls. Revista Eletrônica Direito e Política, Programa de Pós-Graduação Stricto Sensu em Ciência Jurídica da UNIVALI, Itajaí, v.14, n.1, $1^{\circ}$ quadrimestre de 2019. Disponível em: www.univali.br/direitoepolitica - ISSN 1980-7791

caracterizada pelo problema dos direitos sociais, cujo acatamento é considerado como pré-requisito para a consecução da plena participação política"7. Desta forma, a evolução das políticas sociais que erigem no Estado Assistencial acaba perfazendo alguns elementos que estimulam e possibilitam a participação dos cidadãos de um modo geral na política.

O Estado de Bem-estar Social - welfare state - carrega consigo uma série de direitos entabulados como direitos sociais. Eles são muito mais do que direitos meramente individuais, pois em categoria social, demandam do Estado ações ativas e permanentes no sentido de financiar subsídios, remover barreiras sociais e econômicas, a fim de realizar os programas que se fundam em direitos sociais e por eles são legitimados ${ }^{8}$. Esta formatação de Estado erige-se na qualidade de promotor de programas públicos, cujo objetivo é estimular relações entre a economia e a política social juntamente da participação direta dos cidadãos, vez que almeja ampliar a equidade social através das políticas sociais ${ }^{9}$.

Esta participação pode ser vista por meio da ação de Organizações não governamentais (ONGs), sindicatos, participação comunitária, dentre outras modalidades. A atuação destas entidades possibilita um direcionamento das políticas sociais ao encontro dos interesses da sociedade, ajustando questões locais aos respectivos interesses.

Logo, as políticas sociais providas pelo Estado acabam criando uma espécie de elo entre os direitos políticos e sociais, onde o alcance de um grau mínimo de instrução se torna um direito-dever intrinsicamente relacionado ao exercício da cidadania $^{10}$. Neste diapasão, se observados os referidos aspectos que favorecem a efetivação de práticas democráticas e o efetivo exercício da cidadania, vislumbra-se um novo fator decorrente deste Estado assistencial. Veja-se que a partir do momento em que o Estado passa a trazer aos indivíduos direitos sociais

\footnotetext{
7 REGONINI, Gloria. Estado de Bem Estar, p. 416

${ }^{8}$ CAPPELLETTI, Mauro. Juízes legisladores? Tradução de Carlos Alberto Álvaro de Oliveira. Porto Alegre: Sérgio A. Fabris Editor, 1993, p. 41.

9 DRAIBE, Sônia M.; RIESCO, M. Estado de bienestar, desarrollo económico y ciudadania: algunas lecciones de la literatura contemporânea. Serie Estúdios y Perspectivas, México, D.F., n. 55, p. 1-58, 2006, p. 13.

10 REGONINI, Gloria. Estado de Bem Estar, p. 417.
} 
BRUGNOLO MAZAROTTO, Eduardo; GONÇALVES DE QUADROS, Doacir. Ações afirmativas e judicialização da política: um olhar baseado na teoria de John Rawls. Revista Eletrônica Direito e Política, Programa de Pós-Graduação Stricto Sensu em Ciência Jurídica da UNIVALI, Itajaí, v.14, n.1, $1^{\circ}$ quadrimestre de 2019. Disponível em: www.univali.br/direitoepolitica - ISSN 1980-7791

- ainda que mínimos - tal fato passa a estimular a participação popular nas decisões políticas.

Isto porque, quando o indivíduo percebe práticas assistenciais do Estado, por vezes não terá muitas de suas questões individuais exauridas de modo pleno, momento este que tenderá a participar, e quiçá, influir em políticas públicas providas pelo Estado ao reclamar suas pretensões. Nesta linha das individualidades, particulares a cada ser, John Stuart Mill apresenta a ideia, ainda que utilitarista, de que a liberdade inerente à pessoa é carregada por um sentimento progressista, que irá culminar em um desejo pelo aperfeiçoamento de diversos elementos, como por exemplo a política, educação e até mesmo a moral ${ }^{11}$.

Portanto, pode-se verificar como reflexo do Estado de Bem-estar Social um aumento da participação da sociedade nas opções políticas, na medida em que passam a ser receptores de programas políticos que, em tese, Ihes beneficiam, de modo a buscarem associações por meio de associações, tais como sindicados, conselhos comunitários etc.

Ademais, esta formatação de Estado que resulta em um modelo democrático, também irá fomentar a participação popular nos processos decisórios, tendo como objetivo uma participação igualitária da sociedade. Tal aspecto acompanha as práticas assistenciais do Estado, onde cumulados ambos os fatores, de modo que a alteração desta perspectiva que ocorrerá na forma tida como Estado liberal de direito, não se restringirá unicamente às funções a serem executadas pelo Estado, mas sim, com a aglutinação do elemento social ao Estado, este passou a realizar práticas assistenciais. Entretanto, igualmente promoveu uma busca pela ampliação do poder de participação dos indivíduos na esfera pública. Reestruturando o conceito do mecanismo de atuação do Estado, que se emana através da Lei ${ }^{12}$.

\footnotetext{
11 MILL, John Stuart. Sobre a liberdade. Rio de Janeiro: L\&PM Pocket, 2012, p. 128.

12 STRECK, Lenio Luiz; MORAIS, José Luis Bolsan. Ciencia Política e Teoria Geral do Estado. 2. ed. Porto Alegre: Livraria do Advogado, 2001, p. 92.
} 
BRUGNOLO MAZAROTTO, Eduardo; GONÇALVES DE QUADROS, Doacir. Ações afirmativas e judicialização da política: um olhar baseado na teoria de John Rawls. Revista Eletrônica Direito e Política, Programa de Pós-Graduação Stricto Sensu em Ciência Jurídica da UNIVALI, Itajaí, v.14, n.1, $1^{\circ}$ quadrimestre de 2019. Disponível em: www.univali.br/direitoepolitica - ISSN 1980-7791

Além do estímulo à participação, o Estado de Bem-estar Social carrega em sua essência um outro fator que desenvolve certa atuação do Poder Judiciário sob um viés proativo, com interferências claras em questões políticas, muitas delas de caráter discricionário. Sob um olhar ao Poder Judiciário, aos juízes passa a ser difícil não participarem da efetivação destes novos direitos, tornando-os concretos. Passam a controlar e exigir o cumprimento do dever do Estado de intervir ativamente na esfera social, dever este prescrito em lei e que aos juízes cabe fazer cumprir ${ }^{13}$.

Desta feita, é possível notar alguns efeitos que o Estado Social traz ao comportamento de parcela da sociedade e das próprias instituições, ora como provedoras destes recursos, ora como interventores e garantidores do acesso à referida política, como é o caso da forma de atuação do Poder Judiciário. Importante observar a importância do Estado de Bem-estar Social na problemática ativismo judicial, eis que perfaz um dos pontos centrais das causas de disseminação da criatividade judiciário.

Isso porque a doutrina aponta que o Poder Judiciário se fortaleceu e ganhou um status de protagonismo ao passar a atuar como elemento concretizador de direitos e garantias fundamentais ${ }^{14}$. Neste momento, o Judiciário passa a agir de modo proativo na seara de outros Poderes, se colocando perante a opinião pública como um Poder mais acessível e efetivo, entretanto, a necessidade de intervenção do Poder Judiciário remete à possível ausência de ações afirmativas do Estado no cumprimento de suas demandas sociais ${ }^{15}$.

Adiante será abordada, ainda que perfunctoriamente, parte do acervo teórico de John Rawls desenvolvido no livro "Uma teoria de justiça", com a intento de após isso, trazer ao debate os entornos da atuação judicial que visa garantir ações afirmativas às minorias.

\footnotetext{
${ }^{13}$ CAPPELLETTI, Mauro. Juízes legisladores?, p. 42.

14 LEVY, Leonard W. Marbury v. Madison. In: KARST, Kenneth L.; MAHONEY, Dennis J. (eds.). Judicial Power and the Constitution: Selections from the Encyclopedia of the American Constitution. New York: Macmillan, 1990.
}

15 TATE, C. Neal; VALLINDER, Torbjörn (Eds.). The Global Expansion of Judicial Power. New York: New York University Press, 1995. 
BRUGNOLO MAZAROTTO, Eduardo; GONÇALVES DE QUADROS, Doacir. Ações afirmativas e judicialização da política: um olhar baseado na teoria de John Rawls. Revista Eletrônica Direito e Política, Programa de Pós-Graduação Stricto Sensu em Ciência Jurídica da UNIVALI, Itajaí, v.14, n.1, $1^{\circ}$ quadrimestre de 2019. Disponível em: www.univali.br/direitoepolitica - ISSN 1980-7791

\section{ALGUNS COMENTÁRIOS ACERCA DA JUSTIÇA COMO EQUIDADE DE JOHN RAWLS}

Este item visa apresentar, em uma visão geral, alguns aspectos importantes na compreensão da justiça como equidade proposta por John Rawls em seu livro "Uma teoria da Justiça".

John Rawls parte de uma sociedade que é apoiada em normas e em um sistema jurídico válido, apresentando em sua obra não somente uma concepção de justiça, como o título pode equivocadamente induzir, mas também e com maior ênfase, enfrentar alguns aspectos da estrutura básica da sociedade. Por esta razão, o autor é considerado um neocontratualista, na medida em que irá revisitar o pacto social a partir de uma visão claramente diferente de autores clássicos, como Thomas Hobbes, John Locke, dentre outros.

John Rawls não irá discutir a origem do poder ou questões atinentes a legitimidade, mas sim opta por trazer uma nova forma de pensar a respeito das teorias contratualistas na condição de uma associação político-jurídica.

Nesse sentido pode ser enquadrado como um defensor do liberalismo e da democracia constitucional, vez que irá, conforme será discutido adiante, existir um corpo normativo que regulará as condutas não somente dos indivíduos, mas também do Estado.

John Rawls busca discutir, de modo bastante relacionado, alguns elementos centrais da formação de um Estado justo, abordando possíveis formas de articular justiça e liberdade, comportamento moral e problemas da soberania popular quando observado um império da lei. É problematizado como poderiam ser asseguradas as liberdades a partir de uma sociedade organizada cujo consenso parece ser um de seus pilares, mas que virtualmente não parece ser de tão fácil acesso.

A ideia norteadora da justiça como equidade é, portanto, que os princípios da justiça para a estrutura básica da sociedade sejam objeto de um consenso original. São esses princípios que pessoas livres e racionais, preocupadas em promover seus próprios interesses, aceitariam numa posição inicial de igualdade 
BRUGNOLO MAZAROTTO, Eduardo; GONÇALVES DE QUADROS, Doacir. Ações afirmativas e judicialização da política: um olhar baseado na teoria de John Rawls. Revista Eletrônica Direito e Política, Programa de Pós-Graduação Stricto Sensu em Ciência Jurídica da UNIVALI, Itajaí, v.14, n.1, $1^{\circ}$ quadrimestre de 2019. Disponível em: www.univali.br/direitoepolitica - ISSN 1980-7791

como definidores dos termos fundamentais de sua associação, devendo regular todos os acordos subsequentes e especialmente, os tipos de cooperação social que se podem assumir e as formas de governo que se podem estabelecer ${ }^{16}$.

Assim sendo, em um contexto geral extrai-se que John Rawls busca apresentar mecanismos capazes de "reger as desigualdades de perspectivas de vida entre cidadãos, resultantes das posições sociais de partida, das vantagens naturais e das contingências históricas"17.

Para atingimento deste objetivo, elabora uma concepção de justiça que, em suma, seja capaz de distribuir os direitos e deveres fundamentais; determinar uma divisão de vantagens em detrimento da cooperação social; dispor de um conjunto de princípios para garantir os direitos e deveres; fornecer um ponto de vista comum nos conflitos; e pensar em um padrão moral das decisões políticas.

A validação de sua teoria em um viés prático demanda a compreensão de como seria o indivíduo neste Estado hipotético e o conceito de dois princípios basilares de seu referencial, quais sejam, a posição original e o véu da ignorância.

O indivíduo seria plenamente cooperativo, guardando para si um senso de justiça e tendo uma concepção do bem. Ainda, seriam iguais e livres neste Estado, reconhecendo a liberdade dos outros assim como as próprias, de modo que tomariam suas condutas pautadas sempre nestes pontos. No entanto, para que o indivíduo possa ter tais características, impende a compreensão do ponto nodal da teoria Rawlsiana, emanados na posição original e no véu da ignorância.

A posição original, quando do hipotético contrato que John Rawls emprega como instrumento interpretativo, remete ao intento de uma sociedade justa, onde a aplicação da justiça procedimental pura se faria possível desde o início. Parte do pressuposto do estabelecimento de uma cooperação social com novas garantias e legitimidade, onde o contrato social seria um procedimento que objetiva um

${ }^{16}$ RAWLS, John. Uma teoria da justiça. Tradução de Almiro Pisetta e Lenita M. R. Esteves. São Paulo: Martins Fontes, 1997, p. 12.

17 RAWLS, John. Uma teoria da justiça, p. 7. 
BRUGNOLO MAZAROTTO, Eduardo; GONÇALVES DE QUADROS, Doacir. Ações afirmativas e judicialização da política: um olhar baseado na teoria de John Rawls. Revista Eletrônica Direito e Política, Programa de Pós-Graduação Stricto Sensu em Ciência Jurídica da UNIVALI, Itajaí, v.14, n.1, $1^{\circ}$ quadrimestre de 2019. Disponível em: www.univali.br/direitoepolitica - ISSN 1980-7791

consenso geral, pressupondo a aceitação perante as vantagens mútuas de cada cidadão, atingido de modo justo ${ }^{18}$.

Quanto ao véu da ignorância, as partes irão avaliar os princípios deste Estado unicamente com base em considerações gerais, tendo em vista que ninguém saberá qual seu lugar na sociedade, a sua posição de classe ou status social. Não obstante, não conhecem a sorte na distribuição de dotes naturais e habilidades, inteligência, força, dentre outras características particulares a cada ser. Os indivíduos tampouco conhecem traços de sua psicologia, como por exemplo a aversão ao risco ou tendência ao otimismo e pessimismo ${ }^{19}$.

John Rawls afirma ainda que além das características relacionadas ao ser, as partes não conhecem as circunstâncias particulares de sua sociedade, como economia e política, tampouco nível de civilização cultural atingida, ignorando a que geração pertencem nesta sociedade ${ }^{20}$.

Nota-se, portanto, que a leitura conjunta da posição original e do véu da ignorância remete à ideia de que esta nova proposta neocontratualista colocaria as pessoas em posição de igualdade abstrata, onde a tomada de decisões para constituição das premissas do Estado se darão de forma equânime, visto que diante da ignorância das particularidades de cada ser, a tendência é que o resultado das escolhas seja de mútuo benefício.

Aliás, é importante destacar que na posição original, como sendo um status a quo, qualquer consenso é considerado justo, na medida em que não haverá distinção de posição social e outras peculiaridades ${ }^{21}$.

No cerne da posição original, serão discernidos pelos indivíduos os pontos básicos deste modelo associativo, destacando-se os dois princípios da justiça, que perfazem o princípio das liberdades básicas e o princípio da diferença.

\footnotetext{
18 RAWLS, John. Uma teoria da justiça, p. 19.

19 RAWLS, John. Uma teoria da justiça, p. 147.

20 RAWLS, John. Uma teoria da justiça, p. 149.

21 RAWLS, John. Uma teoria da justiça, p. 129.
} 
BRUGNOLO MAZAROTTO, Eduardo; GONÇALVES DE QUADROS, Doacir. Ações afirmativas e judicialização da política: um olhar baseado na teoria de John Rawls. Revista Eletrônica Direito e Política, Programa de Pós-Graduação Stricto Sensu em Ciência Jurídica da UNIVALI, Itajaí, v.14, n.1, $1^{\circ}$ quadrimestre de 2019. Disponível em: www.univali.br/direitoepolitica - ISSN 1980-7791

Quanto ao princípio das liberdades básicas, John Rawls irá afirmar que cada pessoa possui direito igual a um sistema plenamente adequado de liberdades e direitos básicos iguais, compatíveis como um mesmo sistema para todos. De outro norte, no tocante ao princípio da diferença, entende-se que as desigualdades sociais e econômicas devem ser precedidas de duas condições preambulares: em primeiro lugar, devem estar ligadas a funções e posições abertas a todos em condições de justa (fair) igualdade de oportunidades; e, em segundo lugar (princípio da diferença), devem proporcionar a maior vantagem para os membros mais desfavorecidos da sociedade ${ }^{22}$.

Com relação aos princípios apresentados e que são emanados na posição original, extrai-se que sua constituição visa, em um primeiro plano, garantir aos cidadãos o acesso à liberdades e direitos básicos, dos quais poderíamos destacar como sendo aqueles que se manifestam na forma de direitos fundamentais, tais como o acesso à educação, saúde, moradia, assistência social etc.

Por conseguinte, relacionado ao princípio da diferença, compreende-se como sendo o princípio que coloca a todos a igualdade de oportunidades de acesso às funções do Estado. Entretanto, aos que não conseguirem o dito acesso, seja por qual razão for, o Estado terá a obrigação de proporcionar maiores vantagens aos desfavorecidos tentando compensar essas diferenças, visando um equilíbrio nas relações do ente público. Deste princípio se extrai, por exemplo, as políticas assistências de governo, impostos de renda com tabela progressiva, dentre outros.

Todo este conjunto de princípios perfaz para John Rawls a projeção de um resultado que acaba sendo um ponto nodal para o desenvolvimento deste debate. Veja-se que quando a sociedade segue esses princípios, o bem de todos é incluído em um sistema de benefício mútuo e essa afirmação pública, nas instituições, dos esforços de cada homem sustenta a auto estima dos membros da sociedade. O autor se refere, aqui, que autoestima se sustenta reciprocamente e possibilita o respeito aos demais, destacando que quem não se valoriza, dificilmente irá valorizar os outros. Este fenômeno pode desencadear

22 RAWLS, John. Uma teoria da justiça, p. 66. 
BRUGNOLO MAZAROTTO, Eduardo; GONÇALVES DE QUADROS, Doacir. Ações afirmativas e judicialização da política: um olhar baseado na teoria de John Rawls. Revista Eletrônica Direito e Política, Programa de Pós-Graduação Stricto Sensu em Ciência Jurídica da UNIVALI, Itajaí, v.14, n.1, $1^{\circ}$ quadrimestre de 2019. Disponível em: www.univali.br/direitoepolitica - ISSN 1980-7791

problemas na sustentação desta sociedade, a colocando em risco, de forma que a aplicação dos princípios na forma disposta tende a garantir um funcionamento harmônico das instituições ${ }^{23}$.

Desta feita, a emanação dos princípios na justiça como equidade desencadeiam uma tentativa de apresentação de uma ideia de justiça que se paute em valores de igualdade e não obstante, diferenças que buscam ao final, alcançar a igualdade: "Todos os valores sociais - liberdade e oportunidade, renda e riqueza, e as bases sociais da autoestima - devem ser distribuídos igualitariamente a não ser que uma distribuição desigual de um ou de todos esses valores tragam vantagens para todos"24.

De um modo geral, foram expostos alguns dos elementos da teoria da John Rawls. Por óbvio, apenas foram referenciados alguns dos principais elementos abordados pelo autor em questão, no entanto, são os pontos que mais se relacionam com o objeto do presente manuscrito.

Percebe-se da leitura destes elementos levantados, que a justiça como equidade visa permitir que a igualdade seja alcançada até mesmo em situações de diferença, sendo permitido ao Estado as medidas necessárias a fim de proceder tentativas correção de diferenças. Outro ponto importante para a discussão é que, todas as decisões tomadas, se erigem de um pressuposto de aceitação dos indivíduos, vez que foram originados através de um procedimento considerado como correto ou justo, cujo resultado também será apresentado como correto ou justo, qualquer que seja ele, contanto que o procedimento tenha sido aplicado ${ }^{25}$.

Diante de todo o exposto, a teoria de John Rawls na baila de seus dois princípios básicos demonstra que ações afirmativas do Estado na forma de políticas públicas serão cruciais para manutenção da sociedade. Porém, quando estas ações afirmativas falham, não sendo suficientes no alcance das necessidades básicas de parcela dos indivíduos dispostas em um Estado de Bem-estar Social, qual o caminho possível para, de fato, impô-las e concretizá-las?

\footnotetext{
23 RAWLS, John. Uma teoria da justiça, p. 194-195.

24 RAWLS, John. Uma teoria da justiça, p. 66.

25 RAWLS, John. Uma teoria da justiça, p. 92.
} 
BRUGNOLO MAZAROTTO, Eduardo; GONÇALVES DE QUADROS, Doacir. Ações afirmativas e judicialização da política: um olhar baseado na teoria de John Rawls. Revista Eletrônica Direito e Política, Programa de Pós-Graduação Stricto Sensu em Ciência Jurídica da UNIVALI, Itajaí, v.14, n.1, $1^{\circ}$ quadrimestre de 2019. Disponível em: www.univali.br/direitoepolitica - ISSN 1980-7791

\section{A JUdICIALIZAÇÃo dA POLÍtTICA E O DIREITO DAS MINORIAS NAS POLÍTICAS PÚBLICAS}

As políticas públicas, segundo Maria Paula Dallari Bucci, são "programas de ação governamental visando a coordenar os meios à disposição do Estado e as atividades privadas, para a realização de objetivos socialmente relevantes e politicamente determinados"26.

No mesmo sentido dispõem Fábio Konder Comparato, no sentido de que as políticas públicas consistiriam em uma atividade, que se dão através de um conjunto organizado de normas e imperativos legais, que são unificados por uma finalidade, ou seja, um objetivo previamente determinado 27.

As políticas públicas desenvolvem a ideia de que o gestor, respeitada a legislação correspondente e as atribuições de cada esfera de governo, deverá direcionar montante financeiro para concretização de ações afirmativas em áreas específicas, como saúde, educação, segurança pública, dentre outras, áreas estas relacionados ao bojo de um Estado de Bem-estar Social.

O agente político, que na função de representação imanente à seara de uma democracia representativa, igualmente reconhecida no acervo teórico de John Rawls, irá direcionar investimentos de acordo com o seu juízo.

Políticas públicas que se exaurem por meio de ações afirmativas são matérias de competência dos Poderes Executivo e Legislativo, guardadas suas questões específicas. Porém, existem casos cada vez mais frequentes, de intervenção direta do Poder Judiciário na tentativa de compelir os governantes a tomada de determinadas condutas, visando o resguardo dos direitos de minorias. Tais intervenções são denominadas de judicialização da política²8.

\footnotetext{
26 BUCCI, Maria Paula Dallari. Direito administrativo e políticas públicas. São Paulo: Saraiva, 2006, p. 241.

27 COMPARATO, Fábio Konder. Ensaio sobre o juízo de constitucionalidade de políticas públicas. Revista dos Tribunais, São Paulo, v. 86, n. 737, p. 11-22, mar. 1997, p. 353.

28 FONSECA Lorena; COUTO Felipe Fróes. Judicialização da política e ativismo judicial: uma diferenciação necessária. Revista Eletrônica Direito e Política, Itajaí, v. 13, n. 2, $2^{\circ}$ quadrimestre, 2018.
} 
BRUGNOLO MAZAROTTO, Eduardo; GONÇALVES DE QUADROS, Doacir. Ações afirmativas e judicialização da política: um olhar baseado na teoria de John Rawls. Revista Eletrônica Direito e Política, Programa de Pós-Graduação Stricto Sensu em Ciência Jurídica da UNIVALI, Itajaí, v.14, n.1, $1^{\circ}$ quadrimestre de 2019. Disponível em: www.univali.br/direitoepolitica - ISSN 1980-7791

De acordo com Luiz Roberto Barroso, a judicialização da política vai além da mera hermenêutica constitucional, podendo se manifestar por meio de diferentes condutas, que incluem: (i) a aplicação da Constituição em situações não contempladas de modo expresso no texto à revelia do legislador ordinário; (ii) a declaração de inconstitucionalidade de atos normativos, a partir de critérios que vão além da notória violação da Constituição; (iii) a imposição de condutas ou de abstenções ao Poder Público, que se expressam via de regra em políticas públicas $^{29}$.

De outro norte, segundo Ran Hirschl judicialização da política é um termo empregado para traduzir o que, a bem da verdade, são três processos interrelacionados. O primeiro deles seria a judicialização das relações sociais; o segundo na qualidade da expansão da competência dos tribunais e juízes em matéria de políticas públicas; e o terceiro no tocante ao emprego do Poder Judiciário para lidar com a megapolítica ${ }^{30}$.

A judicialização das relações sociais se refere à proliferação do que Hirschl chama de discursos, jargões, regras e processos jurídicos na seara da política e nos processos de criação das políticas públicas. Durante a elaboração destas políticas, é notável que nos processos jurídicos integrantes ao referido se desencadeia a judicialização como um elemento natural de evolução da sociedade ${ }^{31}$.

O segundo conceito da judicialização se encontra na expansão das competências de tribunais e juízes quando relacionados às políticas públicas. Estas intervenções visam, principalmente, agir quando o debate se relacionar a direitos constitucionais e da discussão acerca de limites entre órgãos do Estado. Este tipo de atuação jurisdicional se mostra bastante corriqueira no dia-a-dia das cortes

29 BARROSO, Luís Roberto. Judicialização, ativismo judicial e legitimidade democrática. In: COUTINHO, Jacinto N. de Miranda; FRAGALE FILHO, Roberto; LOBÃO, Ronaldo (orgs.). Constituição \& ativismo judicial: limites e possibilidades da norma constitucional e da decisão judicial. Rio de Janeiro: Lumen Juris, 2011, p. 285.

30 HIRSCHL, Ran. O novo constitucionalismo e a judicialização da política pura no mundo. Revista de Direito Administrativo, Rio de Janeiro, v. 251, p. 139-178, maio 2009, p. 144-145.

31 HIRSCHL, Ran. O novo constitucionalismo e a judicialização da política pura no mundo, p. 142. 
BRUGNOLO MAZAROTTO, Eduardo; GONÇALVES DE QUADROS, Doacir. Ações afirmativas e judicialização da política: um olhar baseado na teoria de John Rawls. Revista Eletrônica Direito e Política, Programa de Pós-Graduação Stricto Sensu em Ciência Jurídica da UNIVALI, Itajaí, v.14, n.1, $1^{\circ}$ quadrimestre de 2019. Disponível em: www.univali.br/direitoepolitica - ISSN 1980-7791

constitucionais, especialmente quando enfrentam direitos fundamentais ou limites dos poderes Executivo ou Legislativo ${ }^{32}$.

Aqui é possível observar que a supramencionada invasão do direito sobre os aspectos sociais e que se desloca à regulação de setores mais desamparados, desencadeia o que Werneck Viana chama de "processo de substituição do Estado e dos recursos institucionais classicamente republicanos pelo judiciário, visando a dar cobertura à criança e ao adolescente, ao idoso e aos portadores de deficiência física"33. Aqui os tribunais e juízes se colocam em um claro papel de protagonismo no envolvimento das questões sociais, literalmente judicializando políticas.

Nota-se que neste segundo ponto, quando se discute os direitos constitucionais como aspectos da judicialização da política, deve-se observar não somente aqueles que são frutos de ações afirmativas do Estado, como por exemplo o acesso à educação ou à saúde, mas também questões processuais, como por exemplo os problemas atinentes ao processo penal, ao qual é destacado por Luiz Werneck Vianna por perfazer cerca de $2 / 3$ do total das matérias judicializadas ${ }^{34}$. Assim sendo, esta visão de judicialização enfoca, prioritariamente, a justiça processual e a igualdade formal junto aos processos decisórios que via de regra se encontram como políticas públicas e muitas delas, provenientes de ações afirmativas.

Aqui observa-se ponto comum com o item anterior quando abordado o Estado de Bem-estar Social, visto que os poderes e competências dos tribunais e juízes restam deveras expandidos nesta formatação de Estado, ao ser permitida a revisão de atos administrativos do Poder Público. Apesar de via de regra a intervenção nesta seara pairar sob elementos procedimentais, possível observar casos em que questões materiais são revistas, formando aqui um ponto de

\footnotetext{
32 HIRSCHL, Ran. O novo constitucionalismo e a judicialização da política pura no mundo, p. 143.

33 VIANNA, Luiz Werneck; BURGOS, Marcelo Baumann; SALLES, Paula Martins. Dezessete anos de judicialização da política. Tempo Social, São Paulo, v. 19, n. 2, p. 39-85, nov. 2007, p. 41.

34 VIANNA, Luiz Werneck; BURGOS, Marcelo Baumann; SALLES, Paula Martins. Dezessete anos de judicialização da política, p. 144.
} 
BRUGNOLO MAZAROTTO, Eduardo; GONÇALVES DE QUADROS, Doacir. Ações afirmativas e judicialização da política: um olhar baseado na teoria de John Rawls. Revista Eletrônica Direito e Política, Programa de Pós-Graduação Stricto Sensu em Ciência Jurídica da UNIVALI, Itajaí, v.14, n.1, $1^{\circ}$ quadrimestre de 2019. Disponível em: www.univali.br/direitoepolitica - ISSN 1980-7791

encontro e desencadeamento de ativismo, consoante será abordado na próxima seção.

Ran Hirschl diz em síntese que, "seja por meio da jurisprudência centrada em direitos fundamentais, seja por meio da revisão judicial de atos administrativos, [...] a judicialização da elaboração de políticas públicas se aproxima de um verdadeiro "governo com juízes"35. O Poder Judiciário neste diapasão deixa de lado uma postura positivista, atuando paulatinamente sob um viés político nos mais diversos casos concretos, visando no resultado final, a assunção dos princípios e direitos fundamentais encartados naquele Estado.

Dobrowolski por sua vez, argumenta que esta judicialização não pretende um "governo de juízes", visto que irá observar quando da intervenção as normas legisladas e a própria separação de poderes, desencadeando ao poder Judiciário elevar-se à condição de um autêntico poder, que conseguirá um papel ativo, ao inovar na ordem jurídica e social, a partir de decisões cuja natureza possui efeitos políticos ${ }^{36}$.

Nota-se neste quesito, discussão acerca de se a juridificação das relações sociais torna o governo representativo democrático passível de administração (a partir de intervenções) por parte de agentes não eleitos, decisões estas que são denominadas como contramajoritárias. Este ponto será no terceiro capítulo abordado, porém convém destacar por ora, que esta discussão perfaz uma das maiores fragilidades da doutrina do ativismo judicial.

O último elemento concernente à judicialização, paira na atuação de juízes e tribunais no que Hirschl chama de "megapolítica". Neste conceito estariam as discussões que possuem o condão de unir ou dividir comunidades, como por exemplo:

A judicialização de processos eleitorais; supervisão judicial de prerrogativas do Poder Executivo em áreas de planejamento macroeconômico ou segurança nacional (o m

35 VIANNA, Luiz Werneck; BURGOS, Marcelo Baumann; SALLES, Paula Martins. Dezessete anos de judicialização da política, p. 145.

36 DOBROWOLSKI, Sílvio. A necessidade de ativismo judicial no Estado contemporâneo. Sequência, Florianópolis, v. 16, n. 31, p. 92-101, dez. 1995, p.97. 
BRUGNOLO MAZAROTTO, Eduardo; GONÇALVES DE QUADROS, Doacir. Ações afirmativas e judicialização da política: um olhar baseado na teoria de John Rawls. Revista Eletrônica Direito e Política, Programa de Pós-Graduação Stricto Sensu em Ciência Jurídica da UNIVALI, Itajaí, v.14, n.1, $1^{\circ}$ quadrimestre de 2019. Disponível em: www.univali.br/direitoepolitica - ISSN 1980-7791

daquilo que é conhecido na teoria constitucional como a doutrina da "questão política"; dilemas fundamentais de justiça restaurativa; corroboração judicial de transformações de regime político; e, acima de tudo, a judicialização da formação de identidades coletivas, processos de construção de nações e disputas a respeito da própria definição - ou raison d'être - da comunidade, talvez o tipo mais problemático de judicialização do ponto de vista da teoria constitucional ${ }^{37}$.

Nesta base conceitual, a interferência do Poder Judiciário nas ações afirmativas do Estado, ao qual ora se denomina judicialização da política, pode ser considerada como medida fruto da harmonização dos Poderes, inclusive podendo ser inserida no já conhecido sistema de checks and balances, também conhecido como sistema de freios e contrapesos.

Considerando a necessidade da existência de controle entre ambos os órgãos estatais, almejando evitar desvios de finalidade e abusos de poder, o sistema de freios e contrapesos propõe uma autonomia relativa de cada Poder, criando mecanismos de controle e correção de atos.

Com a proliferação de direitos fundamentais nas modernas Constituições e a assunção de que eles são princípios que podem colidir em casos específicos, sendo uma exigência social a máxima aplicação de cada um dos direitos fundamentais, uma nova concepção de separação de poderes é necessária. Não mais se entende que direito e política são campos totalmente separados e cuja conexão deve ser reprimida para o bom funcionamento do Estado ${ }^{38}$.

Em termos práticos, é possível visualizar em uma análise perfunctória que as ações afirmativas do Estado visam tornar eficazes os direitos fundamentais entabulados em sua legislação. Muitas dessas políticas aplicadas, objetivam tornar materiais o acesso a liberdades e direitos básicos dispostos na teoria da justiça de John Rawls e que são enquadrados em um Estado assistencial. Aqui

\footnotetext{
37 HIRSCHL, Ran. O novo constitucionalismo e a judicialização da política pura no mundo, p. 146.

38 PAULA, Daniel G. de. Ainda existe separação de poderes? A invasão da política pelo Direito no contexto do ativismo judicial e da judicialização da política. In:

ativismo judicial. Salvador. Jus Podivm. 2011, p. 273. (org.). As novas faces do
} 
BRUGNOLO MAZAROTTO, Eduardo; GONÇALVES DE QUADROS, Doacir. Ações afirmativas e judicialização da política: um olhar baseado na teoria de John Rawls. Revista Eletrônica Direito e Política, Programa de Pós-Graduação Stricto Sensu em Ciência Jurídica da UNIVALI, Itajaí, v.14, n.1, $1^{\circ}$ quadrimestre de 2019. Disponível em: www.univali.br/direitoepolitica - ISSN 1980-7791

vislumbra-se, portanto, o acesso de meios e mecanismos aos menos favorecidos às políticas de saúde, educação, assistência social, dentre outras.

Destarte, por vezes essas ações do Estado acabarão não chegando às pessoas em sua universalidade, ocorrendo lacunas em sua aplicação, o que em um primeiro plano, contrariaria os princípios do Estado. É neste ínterim que a judicilização da política é visualizada, pois acaba sendo a forma de criar concretude à um direito inicialmente tido como abstrato e que, na via judicial, há em tese uma maior probabilidade de sua consagração. Werneck Viana em "17 anos de judicialização da política" afirma que:

A invasão do direito sobre o social avança na regulação dos setores mais vulneráveis, em um claro processo de substituição do Estado e dos recursos institucionais classicamente republicanos pelo judiciário, visando a dar cobertura à criança e ao adolescente, ao idoso e aos portadores de deficiência física. O juiz torna-se protagonista direto da questão social ${ }^{39}$.

No fenômeno em discussão, nota-se um andar paralelo - e que por vezes se cruzará - da política e do direito, ao visualizar um campo que, inicialmente, não poderia sofrer a interseção do Poder Judiciário. Ocorre que, a partir de toda a seara normativa-legal onde se encontra todo o constructo de direitos e garantias fundamentais, haverá a necessidade de interferência daquele para a assunção destes bens e direitos.

Orides Mezzaroba defende a diferenciação das funções institucionais dos agentes eleitos e juízes, sendo que estes últimos quando obrigados a interferir em determinadas políticas públicas, deverão decidir visando sempre a proteção dos bens constitucionais (direitos fundamentais) ${ }^{40}$.

Assim sendo, notório que a interferência do Poder Judiciário nesta seara política acaba tendo como diretriz direitos fundamentais. Outrossim, cumpre ressaltar

\footnotetext{
39 VIANNA, Luiz Werneck; BURGOS, Marcelo Baumann; SALLES, Paula Martins. Dezessete anos de judicialização da política, p. 41.

40 MEZZAROBA, Orides; STRAPAZZON, Carlos Luiz. Direitos fundamentais e a dogmática do bem comum constitucional. Sequência, Florianópolis, n. 64, p. 335-372, jul. 2012, p. 340.
} 
BRUGNOLO MAZAROTTO, Eduardo; GONÇALVES DE QUADROS, Doacir. Ações afirmativas e judicialização da política: um olhar baseado na teoria de John Rawls. Revista Eletrônica Direito e Política, Programa de Pós-Graduação Stricto Sensu em Ciência Jurídica da UNIVALI, Itajaí, v.14, n.1, $1^{\circ}$ quadrimestre de 2019. Disponível em: www.univali.br/direitoepolitica - ISSN 1980-7791

que em regra os maiores receptores da intervenção do Poder Judiciário em ações afirmativas serão as minorias. Ao judicializar a política, não necessariamente isto significa que a política pública foi inexistente, mas ao contrário e via de regra, significa que esta não alcançou uma minoria que é receptora deste serviço público.

Por tal razão, estes indivíduos integrantes de uma minoria não favorecida pela política pública em questão acaba, através da judicialização, tendo a possibilidade de expressar sua necessidade através da eficácia do Poder Judiciário por meio de suas prerrogativas.

Direcionando um olhar à Teoria da Justiça de John Rawls, é neste ponto onde encontram-se os princípios erigidos na mesma, vez que as liberdades e direitos básicos devem ser alcançados a todos os cidadãos, sem margem para exclusões. Da leitura da obra em debate, certamente a judicialização da política se enquadraria como uma medida que visa valores igualitários, vez que há, sem dúvida, falhas nas políticas implantadas pelo Estado.

Ainda que judicialização da política seja uma prática que coloca em questão princípios dogmáticos da democracia, especialmente a separação dos poderes tendo em vista que o Poder Judiciário irá interferir em um aspecto tecnicamente político, a leitura de John Rawls acusa que esta judicialização, especialmente visando as minorias não atendidas, erige-se como um mecanismo próprio para a resolução do conflito.

Pietro Costa reconhece a dificuldade entre a compatibilidade recíproca entre a soberania popular (separação de poderes) e a aplicação dos direitos fundamentais do Estado por outros Poderes que senão o legítimo, vez que a soberania do povo e os direitos fundamentais dos sujeitos são ambos princípios irrenunciáveis e que por tal razão, a convivência de dois "absolutos" princípios gera uma tensão não facilmente superável ${ }^{41}$.

41 COSTA, Pietro. Soberania, Representação, Democracia: Ensaios de História do Pensamento Jurídico. Curitiba: Juruá, 2010, p. 232. 
BRUGNOLO MAZAROTTO, Eduardo; GONÇALVES DE QUADROS, Doacir. Ações afirmativas e judicialização da política: um olhar baseado na teoria de John Rawls. Revista Eletrônica Direito e Política, Programa de Pós-Graduação Stricto Sensu em Ciência Jurídica da UNIVALI, Itajaí, v.14, n.1, $1^{\circ}$ quadrimestre de 2019. Disponível em: www.univali.br/direitoepolitica - ISSN 1980-7791

A garantia de acesso a todos (e especialmente das minorias menos favorecidas) aos direitos fundamentais do Estado, que para John Rawls se encontram no campo do primeiro princípio exaurido na posição original, encontram na judicialização da política a possibilidade de interferência nas ações afirmativas do Estado e que visam manter a justiça das instituições no manejo da máquina pública.

Corroborando para o entendimento acima apresentado, "o controle jurisdicional, por via da decisão judicial, visa essencialmente, que a Constituição seja respeitada por todos, instituições e sociedade e, nesse mister, os Direitos Fundamentais e a consequente proteção das minorias são essenciais" 42 .

Assim, o princípio das justas oportunidades de John Rawls se apresenta enfaticamente no âmbito deste procedimento jurisdicional, vez que, com a igualdade de acesso e oportunidades não equânimes, o Poder Judiciário possui o poder-dever de impelir o Estado em tais práticas. É válido, destarte, que a atuação nesta seara "política" pelo Poder Judiciário se mostra como um verdadeiro mecanismo de trazer concretude à justiça social, exatamente na forma com que o referencial de John Rawls dispôs, possibilitando uma aplicação real dos princípios das liberdades básicas e da diferença até mesmo quando o Poder originalmente competente para tais medidas se mostra omisso ou parcialmente incompetente.

Finalmente, a correlação entre as ações afirmativas do Estado, restringidas neste contexto a direitos fundamentais e a garantia de acesso em justa igualdade de oportunidades, mostra-se em um viés direcionado às minorias, como grande mecanismo de garantia de ordem social justa quando permitida a judicialização através de uma instituição neutra e que visará garantir aos desfavorecidos à assunção de direitos fundamentais do Estado, notoriamente estampados nas diretrizes de um Estado de Bem-estar Social.

\footnotetext{
42 ALVES, Fernando de Brito; MACHADO, Edinilson Donisete. Democracia e judicialização da política - problematizando as decisões judiciais sobre direitos sociais. Revista do Direito Público, Londrina, v. 11, n. 3, p.13-46, dez. 2016, p. 45.
} 
BRUGNOLO MAZAROTTO, Eduardo; GONÇALVES DE QUADROS, Doacir. Ações afirmativas e judicialização da política: um olhar baseado na teoria de John Rawls. Revista Eletrônica Direito e Política, Programa de Pós-Graduação Stricto Sensu em Ciência Jurídica da UNIVALI, Itajaí, v.14, n.1, $1^{\circ}$ quadrimestre de 2019. Disponível em: www.univali.br/direitoepolitica - ISSN 1980-7791

\section{CONSIDERAÇÕES FINAIS}

A leitura da obra maior de John Rawls se mostra deveras válida ao promover, ainda que em um plano abstrato, a construção de uma sociedade justa que é avalizada por instituições equânimes cujas oportunidades são abertas a todos. Esta perspectiva de justiça, ao qual relaciona o Estado de uma forma geral, dissemina a ideia da criação daquele sob uma premissa de igualdade, onde os indivíduos vestindo um véu da ignorância, discernem sobre os princípios básicos deste Estado desprovidos de qualquer intuito particularista.

O Estado, assumindo um cunho assistencialista e que participa do dia-a-dia do cidadão, irá gerir as políticas públicas ao promover ações afirmativas, visando o atingimento de todos, irrestritamente. Entretanto, é sabido que as ações humanas são passíveis de falhas parciais ou integrais e, quiçá, omissões. Nesta senda, em regra serão prejudicados com tais falhas de gestão minorias que dependem destas políticas promovidas pelo Poder Público e que se encontram encartados no cerne dos programas deste Estado.

É neste diapasão que a judicialização da política se mostra como um potencial elemento que permite a assunção destes direitos e garantias básicas, ao passo que interferindo e determinando que o Estado tome certas condutas, promoverá o acesso de uma minoria a direitos fundamentais previstos quando da constituição do Estado em questão.

Ainda que esta atuação política do Poder Judiciário possa ser considerada nociva em um olhar preambular acerca dos elementos básicos da configuração do Estado, sua função maior é garantir a aplicação de todo acervo legal erigido por meio de direitos e garantias fundamentais. Em um paralelo à obra de John Rawls, pode-se interpretar que a judicialização da politica visa garantir o acesso dos indivíduos nos princípios basilares escolhidos quando da posição original.

Conclui-se, desta forma, que este procedimento jurisdicional em sua essência pugna pela garantia da igualdade e liberdade, perfazendo um mecanismo que irá auxiliar as minorias na concretude de bens públicos que não foram lhes dado acesso de forma independente e que sua omissão afronta os próprios princípios 
BRUGNOLO MAZAROTTO, Eduardo; GONÇALVES DE QUADROS, Doacir. Ações afirmativas e judicialização da política: um olhar baseado na teoria de John Rawls. Revista Eletrônica Direito e Política, Programa de Pós-Graduação Stricto Sensu em Ciência Jurídica da UNIVALI, Itajaí, v.14, n.1, $1^{\circ}$ quadrimestre de 2019. Disponível em: www.univali.br/direitoepolitica - ISSN 1980-7791

do Estado. Logo, lê-se a judicialização da política como um meio garantidor de uma sociedade justa, onde todos, sejam integrantes de maiorias e minorias, possuem acesso ao Estado e sua voz será ouvida, obtendo obrigatoriamente uma resposta do Poder Público no sentido de garantir a equidade nas relações.

\section{REFERÊNCIAS DAS FONTES CITADAS}

BARROSO, Luís Roberto. Judicialização, ativismo judicial e legitimidade democrática. In: COUTINHO, Jacinto N. de Miranda; FRAGALE FILHO, Roberto; LOBÃO, Ronaldo (Orgs.). Constituição \& ativismo judicial: limites e possibilidades da norma constitucional e da decisão judicial. Rio de Janeiro: Lumen Juris, 2011.

BUCCI, Maria Paula Dallari. Direito Administrativo e políticas públicas. São Paulo: Saraiva, 2006.

CAPPELLETTI, Mauro. Juízes legisladores? Tradução de Carlos Alberto Álvaro de Oliveira. Porto Alegre: Sérgio A. Fabris Editor, 1993.

COMPARATO, Fábio Konder. Ensaio sobre o juízo de constitucionalidade de políticas públicas. Revista dos Tribunais, São Paulo, v. 86, n. 737, p. 11-22, mar. 1997.

COSTA, Pietro. Soberania, representação, democracia: ensaios de História do Pensamento Jurídico. Curitiba: Juruá, 2010.

DRAIBE, Sônia M.; RIESCO, Manuel. Estado de bienestar, desarrollo económico y ciudadania: algunas lecciones de la literatura contemporânea. Serie Estúdios y Perspectivas, México, D.F., n. 55, p. 1-58, 2006.

DOBROWOLSKI, Sílvio. A necessidade de ativismo judicial no estado contemporaneo. Sequência, Florianópolis, v. 16, n. 31, p. 92-101, dez. 1995.

FONSECA, Lorena; COUTO Felipe Fróes. Judicialização da política e ativismo judicial: uma diferenciação necessária. Revista Eletrônica Direito e Política, Itajaí, v. 13, n. 2, p. 824-854, $2^{\circ}$ quadrimestre 2018. 
BRUGNOLO MAZAROTTO, Eduardo; GONÇALVES DE QUADROS, Doacir. Ações afirmativas e judicialização da política: um olhar baseado na teoria de John Rawls. Revista Eletrônica Direito e Política, Programa de Pós-Graduação Stricto Sensu em Ciência Jurídica da UNIVALI, Itajaí, v.14, n.1, $1^{\circ}$ quadrimestre de 2019. Disponível em: www.univali.br/direitoepolitica - ISSN 1980-7791

HIRSCHL, Ran. O novo constitucionalismo e a judicialização da política pura no mundo. Revista de Direito Administrativo, Rio de Janeiro, v. 251, p. 139178 , maio 2009.

LEVY, Leonard W. Marbury v. Madison. In: KARST, Kenneth L; MAHONEY, Dennis J. (eds.). Judicial Power and the Constitution: Selections from the Encyclopedia of the American Constitution. New York: Macmillan, 1990.

MEZZAROBA, Orides; STRAPAZZON, Carlos Luiz. Direitos fundamentais e a dogmática do bem comum constitucional. Sequência, Florianópolis, n. 64, p. 335-372, jul. 2012.

MICHELMAN, Frank. La democrazia e il potere giudiziario: il dilemma costituzionale e il giudice Brennan. Bari: Dedalo, 2004.

MILL, John Stuart. Sobre a liberdade. Rio de Janeiro: L\&PM Pocket, 2012.

PAULA, Daniel Giotti de. Ainda existe separação de poderes? A invasão da política pelo Direito no contexto do ativismo judicial e da judicialização da política. In: . (org.). As novas faces do ativismo judicial. Salvador. Jus Podivm, 2011.

RAMOS, Elival da Silva. Ativismo judicial: parâmetros dogmáticos. São Paulo: Saraiva, 2010.

RAWLS, John. Uma teoria da Justiça. Tradução de Almiro Pisetta e Lenita M. R. Esteves. São Paulo: Martins Fontes, 1997.

REGONINI, Gloria. Estado de Bem-estar. In: BOBBIO, Norberto et al. (orgs.). Dicionário de política. 5. ed. Brasília: Editora Universidade de Brasília, 2000.

STRECK, Lenio Luiz; MORAIS, José Luis Bolsan. Ciéncia Política e Teoria Geral do Estado. 2. ed. Porto Alegre: Livraria do Advogado, 2001.

TATE, C. Neal; VALLINDER, Torbjörn (eds.). The Global Expansion of Judicial Power. New York: New York University Press, 1995. 
BRUGNOLO MAZAROTTO, Eduardo; GONÇALVES DE QUADROS, Doacir. Ações afirmativas e judicialização da política: um olhar baseado na teoria de John Rawls. Revista Eletrônica Direito e Política, Programa de Pós-Graduação Stricto Sensu em Ciência Jurídica da UNIVALI, Itajaí, v.14, n.1, $1^{\circ}$ quadrimestre de 2019. Disponível em: www.univali.br/direitoepolitica - ISSN 1980-7791

VIANNA, Luiz Werneck; BURGOS, Marcelo Baumann; SALLES, Paula Martins. Dezessete anos de judicialização da política. Tempo Social, São Paulo, v. 19, n. 2, p. 39-85, nov. 2007.

RECIBIDO EM: 09/12/2018

APROVADO EM: 16/04/2019 